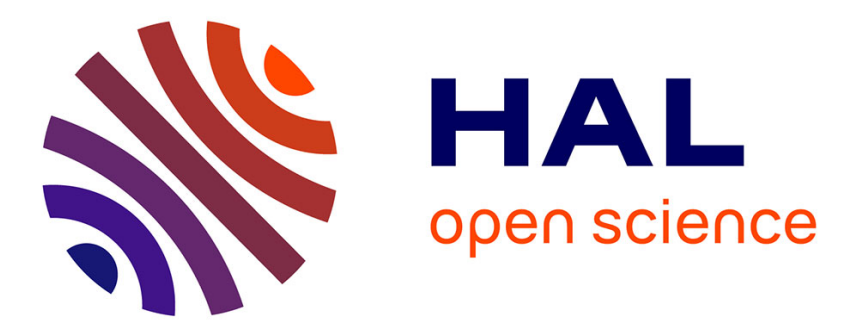

\title{
Net pay determination by artificial neural network: Case study on Iranian offshore oil fields
}

\author{
Pedram Masoudi, Bita Arbab, Hossein Mohammad Rezaei
}

\section{To cite this version:}

Pedram Masoudi, Bita Arbab, Hossein Mohammad Rezaei. Net pay determination by artificial neural network: Case study on Iranian offshore oil fields. Journal of Petroleum Science and Engineering, 2014, Neural network applications to reservoirs: Physics-based models and data models, 123, pp.72 77. 10.1016/j.petrol.2014.07.007 . insu-01382434

\section{HAL Id: insu-01382434 https://hal-insu.archives-ouvertes.fr/insu-01382434}

Submitted on 17 Oct 2016

HAL is a multi-disciplinary open access archive for the deposit and dissemination of scientific research documents, whether they are published or not. The documents may come from teaching and research institutions in France or abroad, or from public or private research centers.
L'archive ouverte pluridisciplinaire $\mathbf{H A L}$, est destinée au dépôt et à la diffusion de documents scientifiques de niveau recherche, publiés ou non, émanant des établissements d'enseignement et de recherche français ou étrangers, des laboratoires publics ou privés. 


\title{
Net Pay Determination by Artificial Neural Network, Case Study on Iranian Offshore Oil Fields
}

Pedram Masoudi, Formerly, Researcher of Petroleum Geoscience, Department of Research and Technology, Iranian Offshore Oil Company (IOOC); Presently, PhD Student at University of Tehran; masoudip@ut.ac.ir

Bita Arbab, Senior Petrophysicist, Department of Petrophysics, Iranian Offshore Oil Company (IOOC)

Hossein Mohammad Rezaei, Head of Department of Petrophysicist, Iranian Offshore Oil Company (IOOC)

\begin{abstract}
Determining productive zones has always been a challenge for petrophysicists. On the other hand, Artificial Neural Networks are powerful tools in solving identification problems. In this paper, pay zone determination is defined as an identification problem, and is tried to solve it by trained Neural Networks. Proposed methodology is applied on two datasets: one belongs to carbonate reservoir of Mishrif, the other belongs to sandy Burgan reservoir. The results showed high precision in classifying productive zones in predefined classes with Classification Correctness Rate of more than $85 \%$ in both geological conditions. Applicability of proposed pay zone determination procedure in carbonate environment is a great advantage of developed methodology. Fuzzified output, being independent of core tests and verification with well tests results are of other advantages of Neural Network-based method of pay zone detection.
\end{abstract}

Keywords: net pay, production, Artificial Neural Network, carbonate, well test, cut-off

\section{Introduction}

Carbonate reservoirs play an essential role in hydrocarbon production these days. Due to Scopus database, from the beginning of 2010 up to December 23th 2013, there are 817 scientific articles that their titles contain "carbonate reservoir", whereas in the meantime, there are only 63 papers that contain "sandy reservoir" or "clastic reservoir" in their titles. This statistics shows high importance of researching about carbonate reservoirs in the recent years. Although there are hundreds of publications about carbonates, still there are huge ambiguities, uncertainties and imprecise interpretations, when 
characterizing these chemical reservoirs. One aspect of this uncertainty is in net pay evaluation. Although petrophysicists utilize cut-off-based method for net pay determination in carbonate rocks, the results are not as satisfactory as in clastic reservoirs. The main reason is that cut-off method is mainly developed in sandstones, and does not work properly in complex and highly heterogeneous environment of carbonates.

Chronologically, the whole story of net pay determination could be categorized in three stages. The primitive stage backs to when petroleum explorers used to identify productive zones while drilling by gas-meter, flourimetric, cased-hole wireline formation tester, Drill Stem Test (DST), etc (Connell et al., 1986; Cooke-Yarborqugh, 1984; Matthews and Russell, 1967; Millikan, 1925).

Following invention of logging technology, the mid-stage of net pay determination started. In this stage, petrophysicists attempted to study the whole drilled interval accurately; thereafter, distinguishing pay zones by thresholds on petrophysical values. Previous publications of cut-off net pay determination (1980-2002) are summarized in a comprehensive work, done by Worthington and Cosentino. In mentioned study, Cut-off parameters of 31 articles, as well as general information of investigated datasets, lithology and hydrocarbon type are listed in a table (Worthington and Cosentino, 2005).

Following this work, very important statistical notes about cut-offs were discussed in (Jensen and Menke, 2006). We can call this paper as a turning point, i.e. start of the third stage in net pay studies, due to incorporating optimization techniques in the process of identifying productive zones. Later, some other optimizations were carried out on cut-off estimation by considering: production plan under the concept of dynamic cut-off (Worthington, 2008); cut-off optimization due to viscosity in (Mahbaz et al., 2011; Masoudi et al., 2011); and finally, application of data-driven and fusion-based techniques in net pay classification (Masoudi et al., 2012a; Masoudi et al., 2012b; Masoudi et al., 2012c).

Current work is following previous data-driven approaches to identify productive zones by Artificial Neural Network (ANN), which is a powerful tool for estimation/ classification. Therefore, general geological and sedimentological aspects of reservoirs, carbonate and clastic, under study are introduced firstly. Then structure of Multi-Layered Perceptron (MLP) and its components are discussed under methodology bullet. Finally, results are shown and compared to cut-off procedure of net determination. It is worthy to mention that well test results were used for training and validating ANNs.

\section{Datasets and Geologic Settings}

Authors selected two different environments to apply the proposed methodology on: First one is carbonate reservoir of Mishrif; and second reservoir is clastic reservoir of Burgan reservoir. Main reason of applying the methodology on Mishrif reservoir was to develop the proposed methodology on a carbonate rock. Of course, applicability of proposed method on a sandy reservoir of Burgan is studied also. 
Mishrif formation is equivalent to Upper Sarvak Formation with the age of Cenomanian- Early Turonian. It is a very important oil reservoir in the Middle East, deposited in a regressive cycle, i.e. starts with basinal (outer self) environment, followed by slope environment, then shoal or reefal environment, finally ends with lagoon environment (Al-Dabbas et al., 2010). Oil field of which Mishrif is investigated through (we call it First Field here) is a relatively small field in the Persian Gulf, with the trend of NorthSouth. In this field, Mishrif formation is overlaid on Khatiyah formation, and is separated from overlaying Laffan Formation by unconformity of Upper Cretaceous. In this field, there are seven wells that Mishrif is drilled wholly, and required petrophysical data and well tests are available through.

Second dataset, belongs to Sandy Burgan reservoir with the age of Middle Cretaceous (Albian era). Burgan is a Member of Kazhdumi Formation (Bashari, 2007; Mahbaz et al., 2011). Based on IOOC reports in the field of which Burgan is investigation (we call it Second Field here), Burgan Member is deposited on unnamed clastics, after a sedimentation gap. In sequence stratigraphy of Burgan Member in an adjacent offshore field, it is revealed that Burgan consists of four sedimentation sequences that each starts from shallow sandy facies, and ends with deeper shaly facies (Honarmand and Moallemi, 2009); in another word, four progressive regime. Available dataset in the Second Field comprised of five drilled wells.

Both structures, First and Second Fields, are of Iranian offshore oil fields in the Persian Gulf. Utilized data in both datasets consist of calculated porosity, shale content and water saturation, as well as well test results for result verification.

\section{Methodologies}

Net pay determination is done by two methodologies: conventional cut-off-based method and ANN-based method. The former method provides a crisp output, whereas the latter ANN-based gives a fuzzified but still discrete output (Masoudi, 2013). The result of cut-off method is considered as a bench mark for assessing proposed method; however well test results have been used for verification.

\section{Conventional Cut-off-based Methodology}

Cut-off determination has been discussed several times in the literature. To be concise, enthusiastic readers are referred to (Mahbaz et al., 2011; Worthington, 2010), and only a brief workflow, which is used in this study is provided below.

In order to select thresholds; firstly, shale-porosity plot is produced in each well to differentiate reservoir facies. Then, borders of each reservoir facies is interpreted as cut-off value of porosity and shale percent. For selecting cut-off of water saturation, histograms of saturation are utilized. Figure 1 shows stages of net pay determination by cut-off method. 


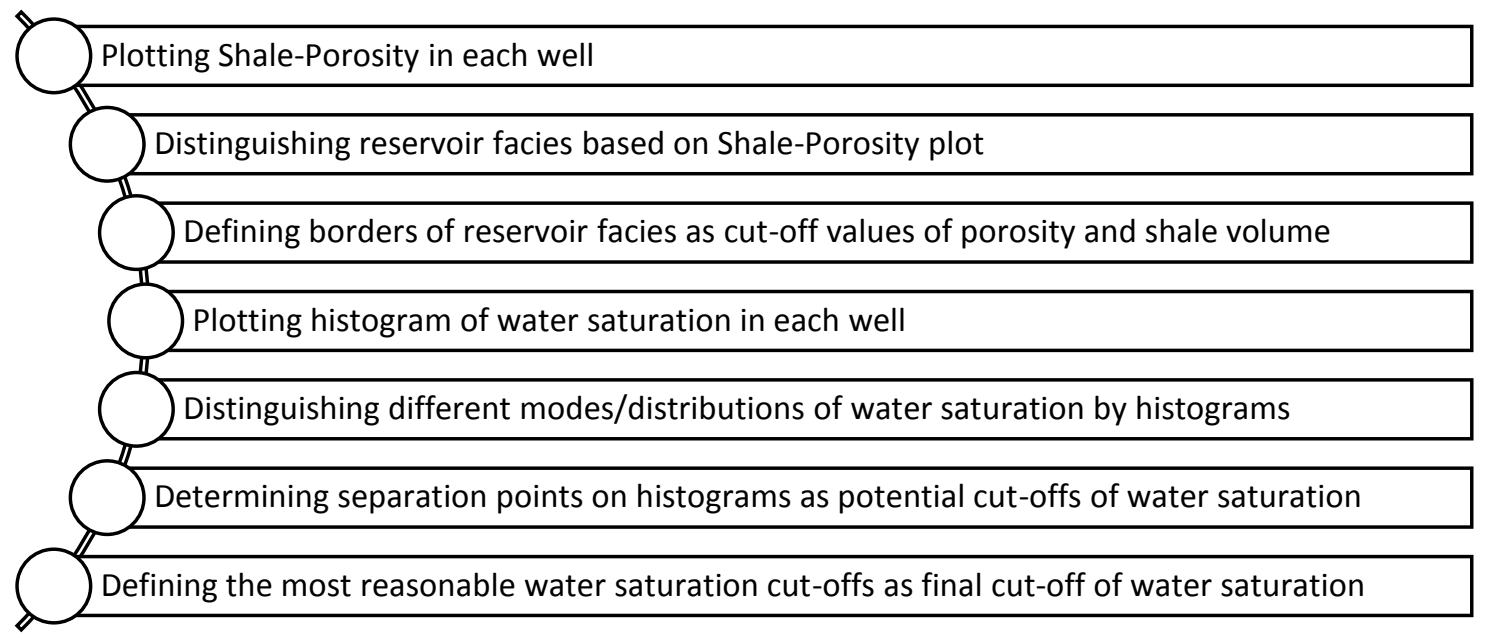

Figure 1 Procedure of net pay determination by cut-off methodology.

In order to clarify introduced algorithm of Figure 1, cross plot of porosity versus shale volume is presented on Figure 2. Directed dashed lines have divided the space into four reservoir facies: 1- low porosity and low shale volume (intermediate reservoir); 2- low porosity and high shale volume (poor reservoir); 3- high porosity and low shale volume (good reservoir); and 4- high porosity and high shale volume (indication of shaly parts). Lack of part 4 in Figure 2 means: Mishrif is a clean reservoir in the interval under study. By applying these two cut-offs; i.e. $4 \%$ for shale volume and $16 \%$ for porosity, we will differentiate part 3 (good reservoir) from other parts.

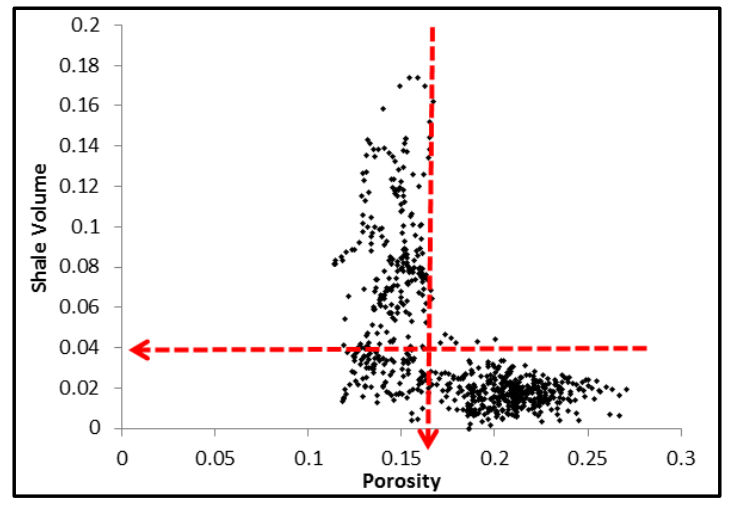

Figure 2 Porosity and Shale Volume cross plot for cut-off determination. Dataset of well2, carbonate Mishrif reservoir.

\section{Proposed ANN-based Methodology}

Inspired from animal central nervous systems, Artificial Neural Network (ANN) is developed under the category of Artificial Intelligent (Al) in order to provide a brain-like tool to identify, estimate, classify or make a decision by a robot, machine program in different situations or conditions. ANNs have various structures. The simplest structure is called Multi-Layered Perceptron (MLP), which consists of 
input layer, output layer and one or more mid-layers, so called hidden layers. Trained ANNs here, have only one mid-layer, i.e. totally three layers in the whole structure.

For any identification procedure, a feature selection method should be used in order to select the most effective inputs amongst. E.g. in identifying net pays, shale volume, porosity, permeability, water saturation, LLD/LLS, LLD, LLS and RHOB are recommended so far (Masoudi et al., 2014). In this work, input layer consists of three neurons, commonly being used by cut-off method, i.e. shale volume, porosity and water saturation (Figure 3). The reason for selecting the same inputs for both net pay determination methods is to investigate efficiency of proposed methodology, while the effect of inputs on both outputs are the same.

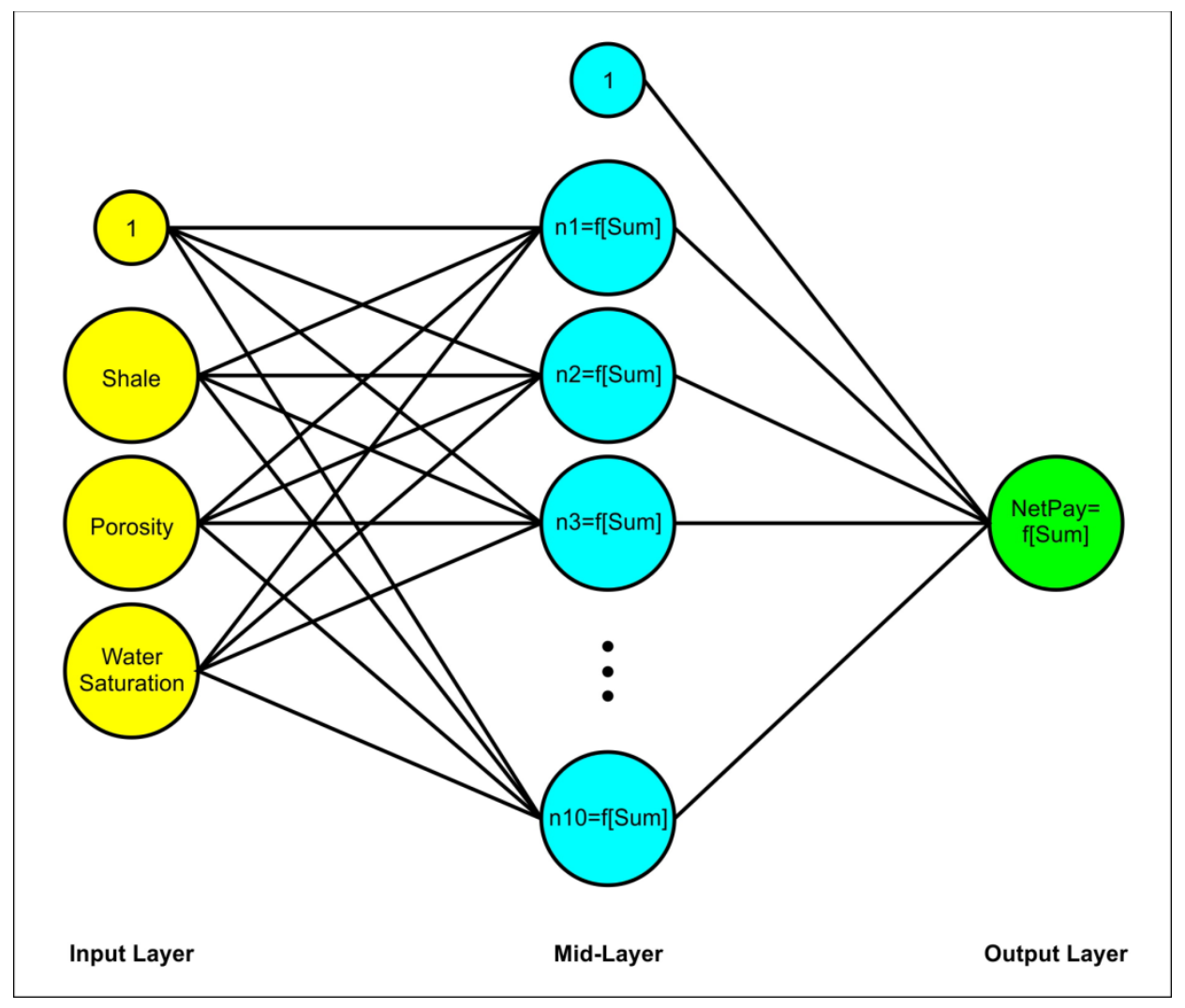

Figure 3 Designed structure for ANN in Mishrif. Number of hidden neurons is 10.

For training the network, Levenberg- Marquardt method is utilized here, which is one of wellknown supervised methods of optimization. Number of neurons in the hidden layer varies from 5 to 50 with the steps of 5 . Every structure (corresponding to a specific number of neurons in the hidden layer) is run 10 times; therefore training is repeated 100 times. Activation function for input and mid-layers is tangent sigmoid, and for output layer is pure-line. The whole dataset is randomly divided into three parts in two stages. In the first stage, $80 \%$ for train-test process and $20 \%$ for validation check. Validation set is kept the same among all trained ANNs for the sake of similarity of validation set, and criteria of selection being comparable. Classification Correctness Rate (CCR) is the criteria of selecting the best trained ANN amongst. In the second stage, train-test dataset is again partitioned randomly to two 
subsets: $70 \%$ (equivalent of $56 \%$ of whole dataset) is considered for training ANNs, and remaining $30 \%$ ( $24 \%$ of whole) is kept for testing trained ANN (Figure 4). For detailed study about the theory and applications of ANN, respected readers are referred to (Bishop, 1995).

\section{Evaluation Criteria}

Confusion matrix is a tool for evaluating preciseness of classifiers. Elements of this matrix show that in which fraction/ percentage, data of actual classes are classified between all available classes (Theodoridis and Koutroumbas, 2003). In order to have a single value, representative of confusion matrix, Classification Correctness Rate (CCR) is calculated by averaging elements on the trace of confusion matrix (Masoudi et al., 2012a).

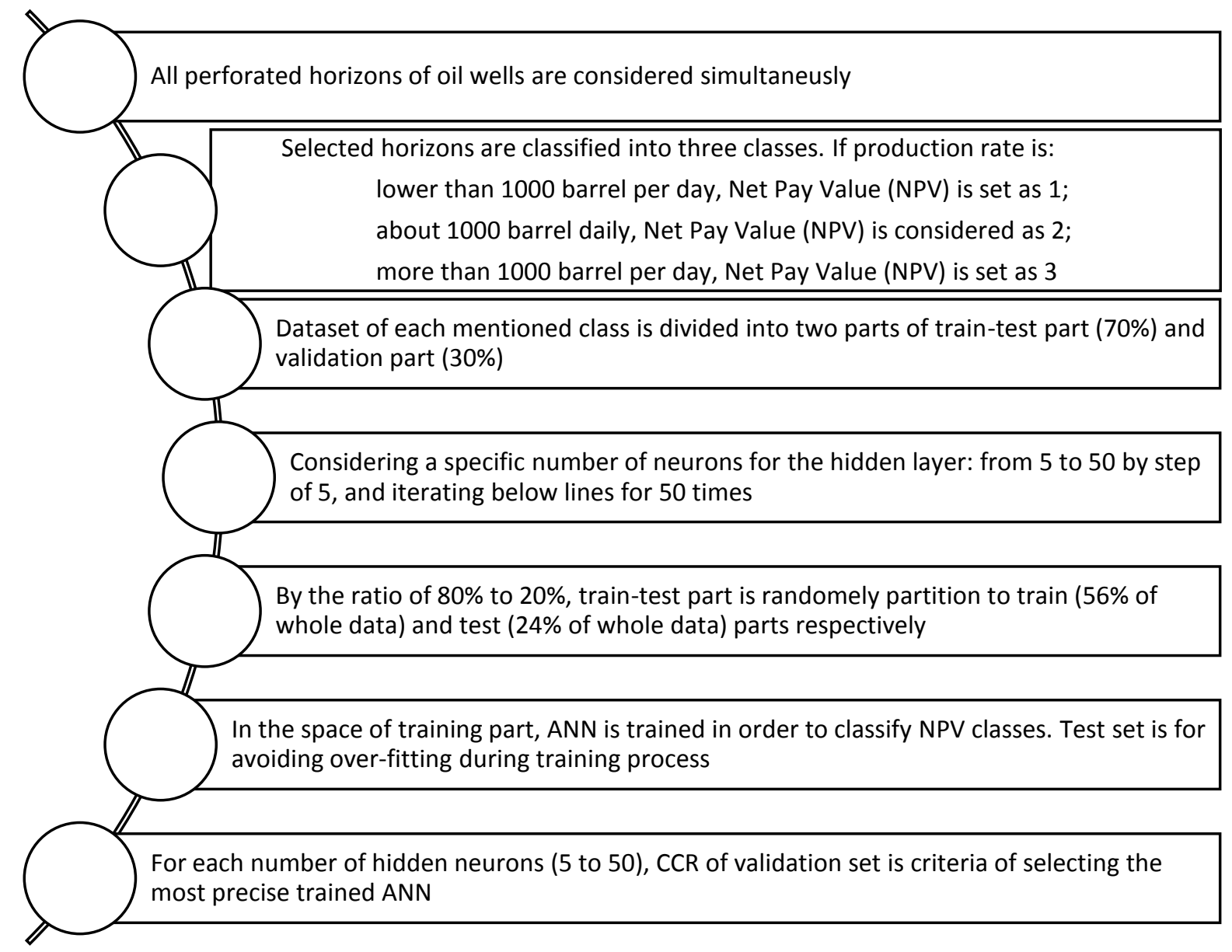

Figure 4 Procedure of training ANNs for net pay determination.

\section{Results and Discussion}


Based on explained introduced flowchart of cut-off determination, Figure 1, cut-offs of porosity, shale volume and water saturation are determined in each well of two available datasets. It should be mentioned that, relatively whole Mishrif is a high-quality reservoir (low-shale and high-porosity), and cut-offs of porosity and shale percentage are only defined to distinguish the cleanest pay zones from whole the interval; in another word, pay zone prioritization is carried out by cut-off method. List of cutoff values is brought for each well in Table 1. Because Burgan reservoir is not as clean as Mishrif, defined cut-offs were closer to ordinary values (Table 2 ).

Table 1 Cut-off determination in seven wells of the First Field for studying carbonate reservoir of Mishrif

\begin{tabular}{cccccccc}
\hline & W1 & W2 & W3 & W4 & W5 & W6 & W7 \\
\hline Shale & $6 \%$ & $4 \%$ & $5 \%$ & $5 \%$ & $2 \%$ & $8 \%$ & $4 \%$ \\
Porosity & $16 \%$ & $16 \%$ & $18 \%$ & $10 \%$ & $20 \%$ & $18 \%$ & $20 \%$ \\
Water Saturation & $60 \%$ & $60 \%$ & $50 \%$ & $50 \%$ & $50 \%$ & $50 \%$ & $60 \%$ \\
\hline
\end{tabular}

Table 2 Cut-off determination in five wells of the Second Field for studying sandy reservoir of Burgan

\begin{tabular}{cccccc}
\hline & W1 & W2 & W3 & W4 & W5 \\
\hline Shale & $48 \%$ & $42 \%$ & $54 \%$ & $60 \%$ & $52 \%$ \\
Porosity & $11 \%$ & $8 \%$ & $4 \%$ & $6 \%$ & $6 \%$ \\
Water Saturation & $55 \%$ & $35 \%$ & $61 \%$ & $35 \%$ & $40 \%$ \\
\hline
\end{tabular}

In Mishrif reservoir, trained ANN with 10 neurons in the hidden layer with CCR of $86 \%$ has the highest CCR value; and in Burgan reservoir, trained ANN with 5 neurons in mid-layer (CCR of 91\%) was selected because of the highest CCR value. Corresponding confusion matrices in testing intervals of each reservoir are shown in Figure 5.

In these matrices, "Real" means "real class"; and "Cl" stands for "Classified by a method". The most precise classification is when observations of real class $x(x=1,2$ or 3$)$ being classified in the same $x$ class. In another word, elements of trace of confusion matrix become maximized. Confusion matrix is a way to show which percent of a specific real class, say class number 1 is classified in class number 1 , here (Figure 5-a) 95\%; which percentage is misclassified in class number 2, here 5\%; and which ratio is misinterpreted in class number 3 , here zero. In fact, it is a measure of correctness of classification (Theodoridis and Koutroumbas, 2003).

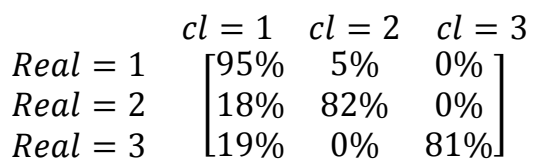

a) Carbonate reservoir of Mishrif

$$
\begin{array}{lcc}
\text { Real }=1 \quad & c l=1 & c l=2 \\
\text { Real }=2 & {\left[\begin{array}{cc}
94 \% & 6 \% \\
12 \% & 88 \%
\end{array}\right]}
\end{array}
$$

b) Clastic reservoir of Burgan

Figure 5 Confusion matrices of ANN-based net pay determination. 
Output of ANN-based methodology, conventional method and testing results of carbonate reservoir of Mishrif is plotted in Figure 6, and for sandy Burgan reservoir is revealed in Figure 7. Following figures, outputs of these two net pay determination methods are compared under four bullets to check the applicability of proposed ANN-based methodology.

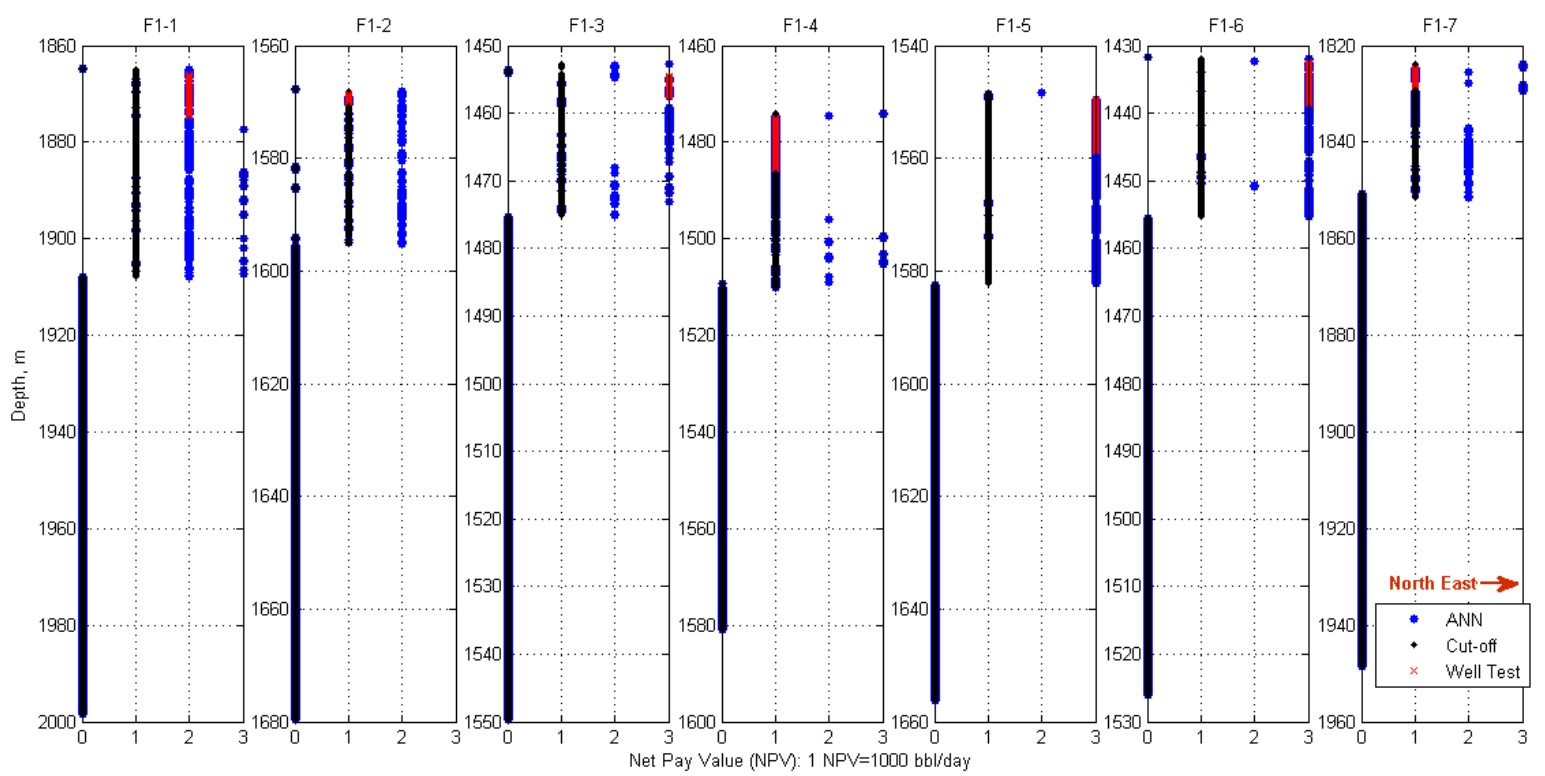

Figure 6 Net pay determination in seven wells of the First Field, studying carbonate Mishrif reservoir. The vertical axe is depth versus the horizontal axe of Net Pay Value.
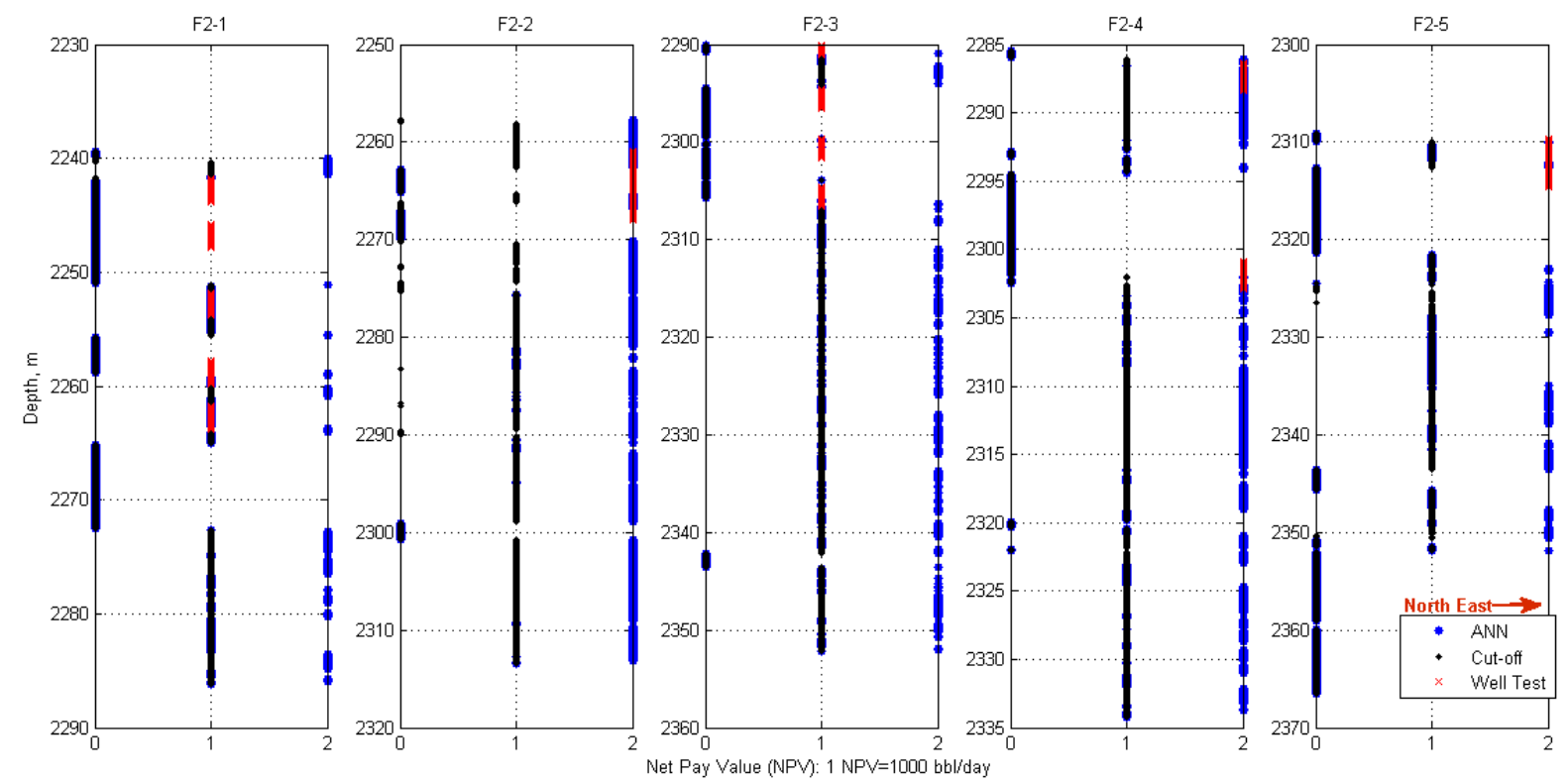
Figure 7 Net pay determination in five wells of the Second Field, studying Sandy Burgan reservoir. The vertical axe is depth versus the horizontal axe of Net Pay Value.

1. In non-pay intervals, both ANN- and cut-off-based methodologies show relatively same results. In another word, when cut-off-based method distinguishes an interval as a non-productive interval, ANN-based gives the same result too.

2. ANN-based methodology is able to show closer behavior to the nature of geology. Although still output of ANN is discrete, it shows a fuzzified behavior; i.e. resulting beyond binary ( 0 or 1 ) output. But cut-off-based methodology provides only crisp output (0/1).

3. In this case, it is difficult to have a realistic value-based assessment of cut-off methodology, because cut-off method provides crisp output, whereas dataset contains other values than 0 and 1 . But assessment of ANN-based method has showed precision of $86 \%$ and $91 \%$ in classifying pay zones in carbonate (Mishrif) and clastic (Burgan) reservoirs, respectively. However these precisions could not be generalized to all carbonate and clastic rocks but authors believe that higher precision of output of sandy reservoirs, comparing to carbonates is a general rule due to heterogeneity of carbonates. High precision of proposed method in carbonates should be marked due to low performance of conventional cut-off-based method in these chemical reservoir rocks.

4. Experimental core analysis reports (SCAL and CCAL) are essential to have a good estimate of porosity, permeability and shale content, when using cut-off methodology. Although in this investigation, core analysis reports are used also, ANN could be trained by raw well-logs and well test results, when there is no core recovery or report. Of course, proposed ANN-based method is not working when there is no well test, whereas conventional cut-off-based method is effective.

\section{Conclusion}

Based on Artificial Neural Networks, a novel procedure of net pay determination is developed in this paper. Proposed method is applied on two datasets with different geological conditions: carbonate and clastic. ANN-based methodology showed closeness (more than $85 \%$ ) to well test results in detecting productive zones in both environments. Other advantages of proposed method are: 1. Being independent of core laboratory reports of porosity, permeability and shale content, in another word, ANN could be trained by raw well-logs too. 2. Providing fuzzified output, which is more compatible with the wild nature of reservoirs, especially carbonates. It is worthy to highlight that ANN-based showed precise results in carbonate rocks, which makes it highly practical in these reservoirs, when other methodologies does not work properly. Ability of training and validating with well test results is another great benefit of ANNs that makes the output of trained ANNs, very close to the real criterion, well test, that we hope to have an estimate of it through drilled wells. 


\section{Nomenclature}

\begin{tabular}{|c|c|}
\hline Abbreviation & Description \\
\hline $\mathrm{Al}$ & Artificial Intelligent \\
\hline ANN & Artificial Neural Network \\
\hline CCAL & Core Analysis \\
\hline CCR & Classification Correctness Rate \\
\hline $\mathrm{Cl}$ & Classified \\
\hline DST & Drill Stem Test \\
\hline$F()$ & Activation Function \\
\hline $\mathrm{F} 1$ to $\mathrm{F} 7$ & Field number 1 to Field number 7 \\
\hline IOOC & Iranian Offshore Oil Company \\
\hline LLD & Deep Laterolog Resistivity \\
\hline LLS & Shallow Laterolog Resistivity \\
\hline MLP & Multi-Layered Perceptron \\
\hline NPV & Net Pay Value \\
\hline RHOB & Bulk Density Log \\
\hline SCAL & Special Core Analysis \\
\hline Sum & Summation \\
\hline W1 to W7 & Well number 1 to Well number 7 \\
\hline
\end{tabular}

\section{Acknowledgment}

The authors would like to acknowledge Iranian Offshore Oil Company for permitting in publishing scientific achievements of the investigation. Also many thank to Professor Tahar Aïfa, respected editor, and anonymous reviewers, who has definitely played an important role in improvement of the work. 


\section{References}

Al-Dabbas, M., Al-Jassim, J. and Al-Jumaily, S., 2010. Depositional environments and porosity distribution in regressive limestone reservoirs of the mishrif formation, Southern Iraq. Arabian Journal of Geosciences, 3(1): 67-78.

Bashari, A., 2007. Integrated 3D seismic and petrophysical data of the Sarvak formation in the Persian Gulf. First Break, 25(11): 45-53.

Bishop, C.M., 1995. Neural Networks for Pattern Recognition. CLARENDON PRESS, Oxford.

Connell, D.L., Coates, J.A. and Frost, D.A., 1986. Development of a Fluorimetric Method for Detection of Pay Zones During Drilling With Invert Muds. SPE Formation Evaluation, 1(6): 595-602.

Cooke-Yarborqugh, P., 1984. Reservoir Analysis By Wireline Formation Tester: Pressures, Permeabilities, Gradients And Net Pay. The Log Analyst, 15(6): 36-46.

Honarmand, J. and Moallemi, S.A., 2009. Lithofacies Analysis, Sedimentary Environment and Sequence Stratigraphy of Burgan Formation, North of the Persian Gulf. Stratigraphy and Sedimentology Researches, 25(2): 135-150.

Jensen, J.L. and Menke, J.Y., 2006. Some Statistical Issues in Selecting Porosity Cutoffs for Estimating Net Pay. PetroPhysics, 47(4): 315-320.

Mahbaz, S., Sardar, H., Namjouyan, M. and Mirzaahmadian, Y., 2011. Optimization of reservoir cut-off parameters: a case study in SW Iran. Petroleum Geoscience, 17(4): 355-363.

Masoudi, P., 2013. Identifying Net Pay Zones in Oil Wells by Artificial Neural Network and DempsterShafer Theories. In: I.P.G.O. Patent Division, State Organization for Registration of Deeds and Properties (Editor), Iran.

Masoudi, P., Asgarinezhad, Y. and Tokhmechi, B., 2014. Feature selection for reservoir characterisation by Bayesian network. Arabian Journal of Geosciences: 1-13.

Masoudi, P., Tokhmechi, B., Ansari Jafari, M., Zamanzadeh, S.M. and Sherkati, S., 2012a. Application of Bayesian in determining productive zones by well log data in oil wells. Journal of Petroleum Science and Engineering, 94-95(0): 47-54.

Masoudi, P., Tokhmechi, B., Bashari, A. and Jafari, M.A., 2012b. Identifying productive zones of the Sarvak formation by integrating outputs of different classification methods. Journal of Geophysics and Engineering, 9(3): 282-290.

Masoudi, P., Tokhmechi, B., Jafari, M.A. and Moshiri, B., 2012c. Application of Fuzzy Classifier Fusion in Determining Productive Zones in Oil Wells. Energy Exploration and Exploitation, 30(3): 403-415.

Masoudi, P., Tokhmechi, B., Zahedi, A. and Jafari, M.A., 2011. Developing a Method for Identification of Net Zones Using Log Data and Diffusivity Equation. Journal of Mining and Environment, 2(1): 5360.

Matthews, C.S. and Russell, D.G., 1967. Pressure Buildup and Flow Tests in Wells. : . Society of Petroleum Engineers of AIME: 163.

Millikan, C.V., 1925. Use of Gas Meters for Determination of Pay Strata in Oil Sands. 183-195.

Theodoridis, S. and Koutroumbas, K., 2003. Statistical Pattern Recognition. Elsevier, USA.

Worthington, P.F., 2008. The Application of Cutoffs in Integrated Reservoir Studies. SPE Reservoir Evaluation \& Engineering, 11(6): pp. 968-975.

Worthington, P.F., 2010. Net Pay-What Is It? What Does It Do? How Do We Quantify It? How Do We Use It? SPE Reservoir Evaluation \& Engineering, 13(5): pp. 812-822.

Worthington, P.F. and Cosentino, L., 2005. The Role of Cut-offs in Integrated Reservoir Studies. SPE Reservoir Evaluation \& Engineering, 8(4): pp. 276-290. 
